\title{
INCORPORACION DE FOSFATO EN CHARA HISPIDA L.
}

\section{J.A. Fernández García}

Dpto. de Fis. Vegetal. Facultad de Ciencias. Universidad de Málaga.

Palabras clave: uptake, Phosphate, macrophytic vegetation.

\author{
ABSTRACT \\ PHOSPHATE INCORPORATION IN CHARA HISPIDA L.
}

In this paper phosphate exchange on Chara hispida L. has been measured at different conditions of light and initial phosphate concentrations. The phosphate incoporation is higher in ligth than in the dark: 777.8 pmol. g. ${ }^{-1} \mathrm{~s}^{-1}$ and 500 pmol. g. ${ }^{-1} \mathrm{~s}^{-1}$, respectively. The initial rate of phosphate incorporation is proportional to the initial concentration, which, furthermore, determines the final external equilibrium concentration in the culture medium.

\section{INTRODUCCION}

La incorporación de fosfato y sulfato en characeas es activa incluso en contra de gradiente electroquímico entre la vacuoia y el medio externo (Robinson, 1969a; Hoagland y Davies, 1923, 192 ); Saddler. 1970a; Smith. 1966). Según erios resuliados tiene que existir, en alguna sarte entre la vacucla " el medio cxterno un transporlauor espocifico. ya sea en el plasmalema o en el tonoplasto.

El objeto de este trabaio es cuantificar la cntrada de fosfato a las células de $C$. hispida partiendo de conccntraciones naturales. ya que los experimentos para dilucidar esta cinética se realizaron con cantidades de fósforo que el macrófito jamás encontrará en todo su ciclo vital (Smith, 1966).

Los objetivos concretos fueron tres:

1.-Medir la tasa de incorporación de fosfato en $C$. hispida partiendo de concentraciones naturales de fosfato tanto en luz como en oscuridad.

2.-Determinar la influencia de la concentración inicial de fósforo en las tasas de incorporación.

3.-Determinar cuál es la concentración externa de equilibrio, esto es, la concentración de fósforo en el medio externo a la cual ya no existe intercambio neto de fosfato.

Limnética 2: 305-310(1986)

O Asociación Española de Limnología, Madrid. Spain

\section{METODOLOGIA}

Para alcanzar los anteriores objetivos se realizaron experimentos en el laboratorio con material recogido con una draga de cuchara en Wellbank Quarry, lago natural situado al norte de Dundec. El material se transportaba al laboratorio en bolsas de plástico y una vez alli se cortaban los ápices y se situaban en un medio de cultivo adecuado (Andrews y Raven, en prensa) a $10^{\circ} \mathrm{C}$. con luz artificial de igual intensidad que la usada luego en los experimentos.

Al menos diez horas antes de iniciar los experimentos, los ápices se seleccionaban, se determinaba el peso fresco y se situaban en los botes de incubación en una proporción aproximada de $1 \mathrm{~g}$. de peso fresco por cada $100 \mathrm{ml}$. de medio de cultivo.

El medio de cultivo que se añadía a los botes en ese momento (en la preincubación) era igual al anterior (Andrews y Raven, en prensa) pero no contenía fósforo. Si se omite la preincubación en un medio de cultivo libre de fósfoi-o, la tasa de incorporación inicial queda enmascarada por una alta tasa de excreción (Figura 1). En Scencedesmus sp. ocurre algo similar con cultivos incubados sin deficiencia de fósforo (Villalobos, inédito).

Después de añadir una determinada cantidad de fosfato se seguía su desaparición tomando muestras 


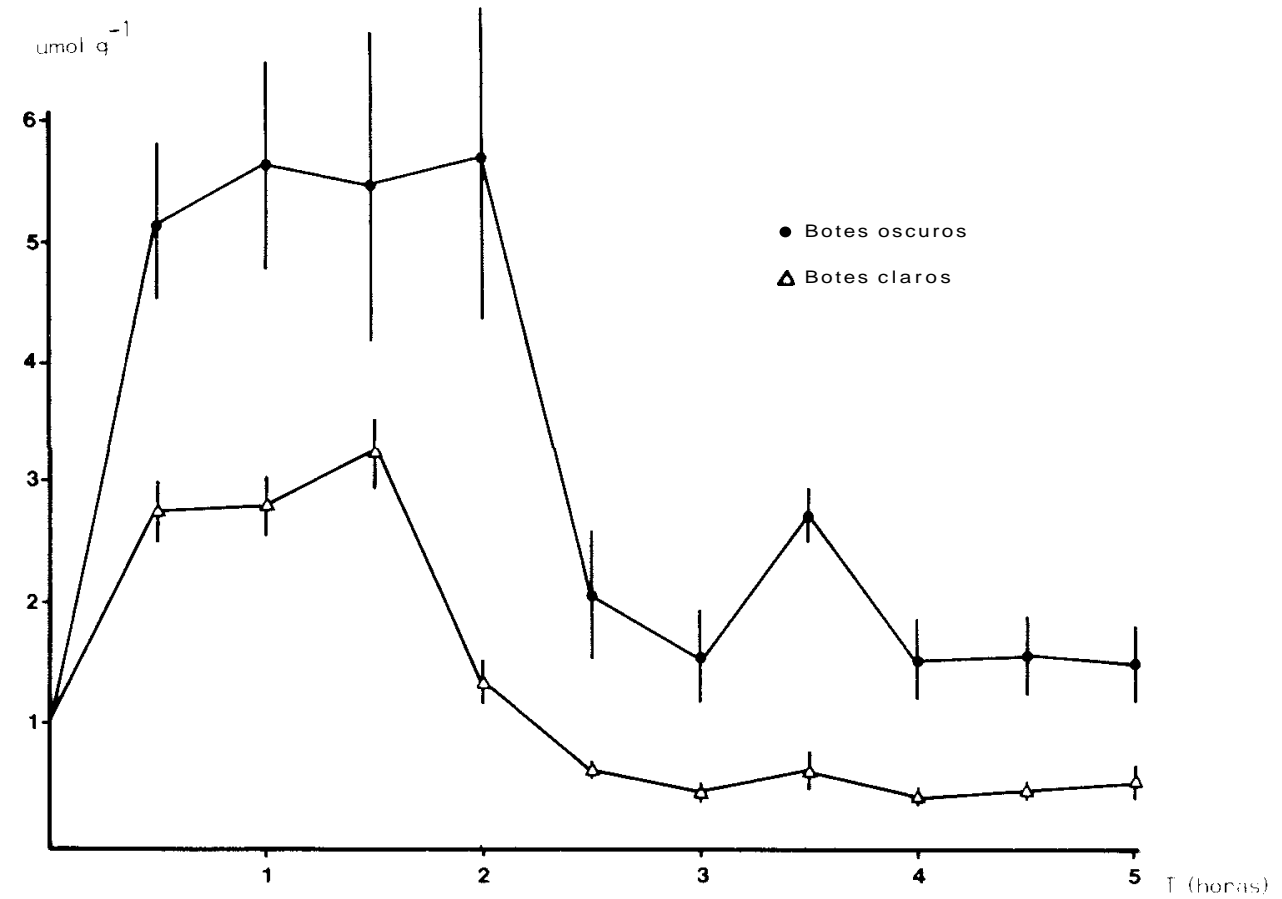

Figura 1.-Representación de la variación de ion foslàto con el tiempoen botes sin preincubación en medio libre de fósforo. Variation of external phosphate concentration with time in flasks without preincubation in a medium phosphorus-free.

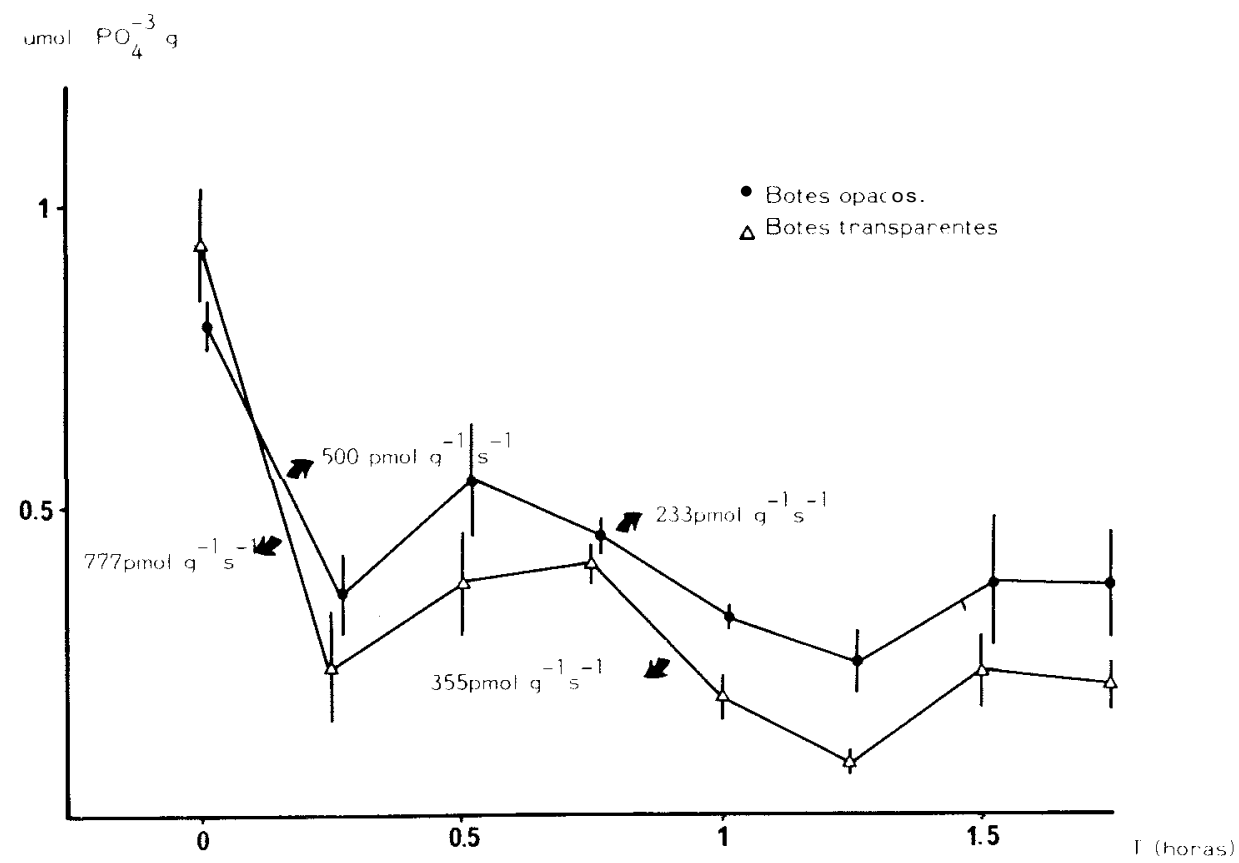

Figura 2.- Representación de la variación de la concentración de fosfato con respecto al tiempo con preincubación en medio libre de fósforo. Sobre la gráfica se especifican los valores de las tasas de incorporación máxima y mínima.

Variation of external phosphatc concentration with time in flasks preincubated in a phosphorus-free mediuni. 


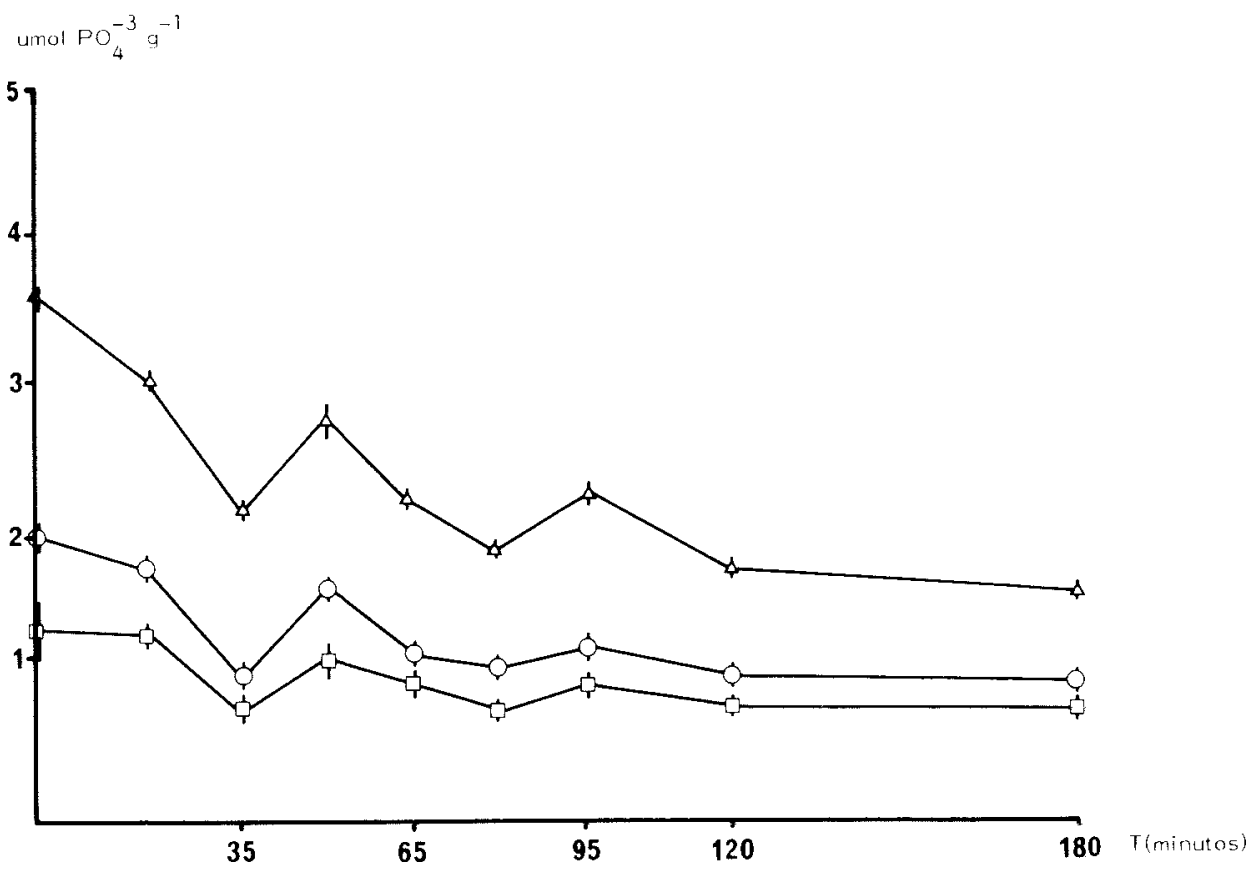

Figura 3.-Representación de la variación de la concentración de ion fosfato con respecto al tiempo partiendo de concentraciones iniciales distintas.

Variation of the external arnount of phosphate against time starting from differents initial phosphate concentrations in the culture medium.

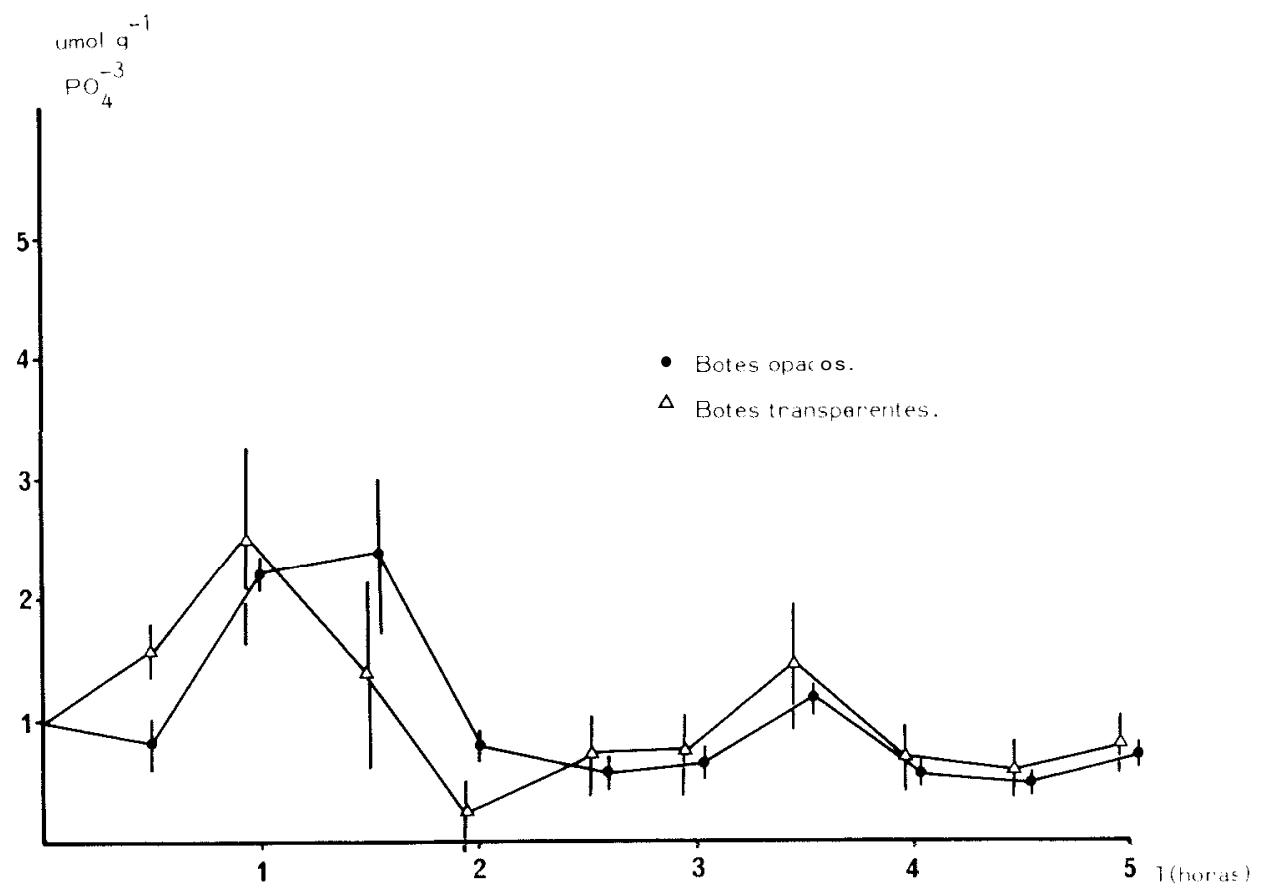

Figura 5.-Representación de la variación de la concentración de fosfato con respecto al tiempo sin agitación continua. Varation of external phosphate concentration aganst time withouth continuous shaking. 
de $1 \mathrm{ml}$. para cada intervalo de tiempo. La concentración de fósforo se determinó con el método de Fernández et al., (1985) en su versión manual, eliminando los pasos previos usados para eliminar las interferencia モon silicatos y arsenatos que no estaban presentes en el medio de cultivo.

Todos los experimentos, excepto el de cuyos resultados se presentan en la figura 5, se hicieron con agitación continua suave. Finalmente las diferentes concentraciones de fosfato se referían a peso seco $(24 \mathrm{~h}$. $80^{\circ} \mathrm{C}$.).

\section{RESC'LTADOS}

En la Figura 1 se presenta la variación de la cantidad de fósforo externo cuando los ápices han sido preincubados en el medio de cultivo completo (Andrews y Raven, en prensa). Durante las dos primeras horas se observa una liberación de fosfato mayor en oscuridad que en luz.

Cuando los ejemplares son preincubados en un medio de cultivo libre de fósforo la primera respuesta es una incorporación con una tasa inicial mayor en luz que en oscuridad: 777.8 pmol. $\mathrm{g}^{-1} \mathrm{~s}^{-1}$ frente a 500 pmol. $\mathrm{g}^{-1} \mathrm{~s}^{-1}$. Las concentraciones de equilibrio finales son mayores en oscuridad que en luz: $0.38 \mathrm{~mol}$. $\mathrm{g}^{-1}$ y 0.21 mol. $\mathrm{g}^{-1}$ respectivamente (Figura 2).

En la figura 3 se representa la variación de la concentración externa de fosfato partiendo de concentraciones iniciales diferentes; como puede verse la tasa inicial es mavor cuanto más alta es la concentración de partida. Asimismo la concentración final de equilibrio sigue la misma pauta.

Las tasas iniciales de incorporación son proporcionales a la cantidad de fosfato inicial añadida:

$$
\text { (1) } \quad V=4.03 \times 10^{-10} \mathrm{P}-3.27 \times 10^{-11} \quad \mathrm{r}^{2}=0.95
$$

donde: $\mathrm{V}$ es la tasa de entrada de fosfato en los primeros 35 minutos y $\mathrm{P}$ la concentración inicial de fosfato añadida al medio de cultivo (expresadas en mol $\mathrm{g}^{-1} \mathrm{~s}^{-1} \mathrm{y} \mathrm{mol} \mathrm{g}^{-1}$ respectivamente).

Cuando los experimentos se realizaban sin agitación, las tasas de incorporación son menores o negativas (hay liberación de fosfato) y las diferencias entre botes transparentes y opacos son irrelevantes.

\section{DISCUSION}

Los resultados de Smith (1966) en Nitella Iranshlucens muestran que la incorporación de fosfato sigue una cinética de saturación típica que sugiere algún proceso activo relacionado con la entrada de fosfato. además la incorporación queda inhibida en presencia de desacopladores de la síntesis de ATP. La saturación de los transportadores de membrana se da a tan altas concentraciones, $4.000 \mathrm{uM}$ aproximadamente (Smith, 1966), que se elimina la posibilidad de un freno de la cinética de entrada por exceso en la cantidad de fosfato externo, incluso con concentraciones cinco veces superiores (figura 4) a las máximas a las que vive el macrófito (Andrews, 1982).

En cuanto a las tasas de entrada. los resultados de este trabajo las sitúan por debajo del rango que da Smith (1966) para N translucens y Raven (1981) para C corallina (Tabla 1$)$.

Los datos obtenidos en luz y en oscuridad, sin agitación coinciden con los de Smith (1966) donde las diferencias entre las tasas de incorporación a bajas concentraciones, en esas condiciones no son importantes.

En los experimentos con agitación, ambas cinéticas son diferentes. debido a que, a bajas tempcraturas. la diferencia entre el aporte energético con luz y sin luz es importante. En Scenedesmus sp. con temperaturas elevadas $\left(23^{\circ} \mathrm{C}\right)$ no existen $\mathrm{C}:$ ferencias entre las velocidades de entrada de luz y en oscuridad (Villalobos. inédito).

Las concentraciones finales de equilibrio que se han obtenido (0.38-0.21 mol g-1) coinciden con las de Bieleski (1973) y son más altas que las teóricas calculadas de la ecuación (1) cuando no hay flujo de fosfato $\left(0.08 \mathrm{pmol} \mathrm{g}^{-1}\right)$.

Esta diferencia podría deberse a excreción. liberación por parte de compuestos inorgánicos que contienen fósforo o saturación de los transportadores de membrana por la cantidad de fósforo interno por un mecanismo análogo al descrito por Glass (1976) para el potasio. aunque gran parte del fósforo es retirado a la vacuola por encima de una determinada cantidad en el citosol (Smith, 1966; Raven, 1974a).

\section{CONCIUSIONES}

La tasa de incorporación de fosfato, partiendo de concentraciones naturales, en luz es mayor que en oscuridad: 777.8 pmol g-' $\mathrm{s}^{-1}$ frente a $500 \mathrm{prnol} \mathrm{g}^{-1} \mathrm{~s}^{-1}$.

La tasa inicial (primeros 35 minutos) de entrada dc fósforo es proporcional a la cantidad de fósforo presente en el medio de cultivo. La relación entre ambas variables queda expresada por la ecuación: $\mathrm{V}=4.03 \times 10^{-10} \mathrm{P}-3.27 \times 10^{-11}$ con un $\mathrm{r}^{2}$ de 0.95 . (Valores de $\mathrm{P}$ expresados en $\mathrm{mol} \mathrm{g}^{-1} \mathrm{y}$ de $\mathrm{V}$ en mol $\mathrm{g}^{-1} \mathrm{~s}^{-1}$ ).

La concentración externa de equilibrio oscila entre 0.38 y $0.21 \mathrm{pmol} \mathrm{g}^{-1}$, y es mayor en oscuridad que en luz. Por otra parte depende dc la concentración inicial de fosfato al iniciar cada experimento: o mayor concentración inicial. mayor es la concentración final de equilibrio. 

ESPECIE

Nitella transhucens

Chara corallina

Chara hispida

\author{
TASA DE INCORPORACION \\ 40-5 17 \\ $10-129$ \\ luz $27-60$ \\ Osc. $18-38$
}

\section{REFERENCIA}

Smith (1966)

Raven (1981)

Este trabajo

Tabla 1.-Comparación de las tasas de incorporación de fosfatoen distintos autores para las distintas especies. * Valores expresados en pmol, por gramo de peso frescoy por segundo.

\section{AGRADECIMIEN'TOS}

Quiero agradecer al Prof. Raven su hospitalidad y las facilidades para la realización de este trabajo en su laboratorio, así como las sugerencias y el espíritu crítico con que se discutieron los resultados. Al Prof Niell, los comentarios sobre el trabajo y la revisión final del manuscrito.

\section{BIBLIOGRAFIA}

Andrews, M. 1982. Ecological and Physiological studies on C'huru hispida L. Ph. D. Thesis. University of Dundee. 290 pp.

Andrews, M. and Raven, J.A., en prensa. Culture of Chara hispida L.

Bieleski, R.L., 1973. Phosphate pools, phosphate transport, and phosphate availability. Annu. Rev. Plant. Physiol. 24, 225-252.

Fernández, J.A., Niell, F.X., and Lucena, J., 1985. A rapid and sensitive automated determination on phosphate in natural waters. Limnol Oceanogr. 30(1), 227-230.

Glass, A.D.M. 1976. Regulation of potassium absorption in barley roots. An allosteric model. Plant. Physiol. 58, 33-7.

Hoagland, D.R. and Davies, A.R., 1929. The intake and incorporation of ions by plant cells. Protoplasma, 6, 610-626.

Raven, J.A. 1974a. Phosphate transport in Hydrodictyon africanum. New Phytol., 73, 421-432.

Raven, J.A. 1981. Nutritional strategies of submerged benthic plants: the acquisition of $c, n$ and $P$ by rhizophytes and haptophytes. New Phytol., 88, 1-30.

Robinson, J.B. 1969a. Sulphate influx in characean cells. I general characteristics. J. Exptl. Bot., 20, 201-211.

Saddler, H.D.W. 1970a. The ionic relations of Acetabularia mediterranea. J. Exptl. Bot., 21, 345-359.

Smith, F.A. 1966. Active phosphate uptake by Nitella translucens. Biochem. Biophys. Acta. 126, 94-99. Villalubos, J.A.. en prensa. Incorporación de fosfato en el fitoplancton en el embalse eutrófico de La Concepción (Istan). Tesina de Licenciatura. Universidad de Málaga. 